\title{
Synthesis, Spectroscopic and Quantum Chemical Studies of a Novel Cis-dioxomolybdenum(vi) Thiosemicarbazonate Complex
}

\author{
Berat İlhan Ceylan, Ayberk Yılmaz, Olcay Bölükbaşı, and Bahri Ülküseven
}

\begin{abstract}
The synthesis and characterization of dioxomolybdenum(VI) chelate complexes with 5-chloro-4methyl-2-hydroxybenzophenone S-methyl-4phenylthiosemicarbazone $(\mathrm{L})$ in the form of $\left[\mathrm{MoO}_{2}(\mathrm{~L}) \mathrm{D}\right]$ where $D$ is the nitrogen donor ligand, namely pyridine in this complex system. The mixed-ligand complexes were characterized by using elemental analysis, UV-Vis, Mid-IR and ${ }^{1}$ H-NMR spectroscopic techniques. In addition, optimized geometries and vibrational wavenumbers of the complexes were calculated DFT/B3LYP functional with LANL2DZ basis set. The assignment of the vibrational modes was performed based on the total energy distribution (TED).
\end{abstract}

Index Terms-Benzophenone, thiosemicarbazone, dioxomolybdenum(VI), vibrational spectra, TED, NBO.

\section{INTRODUCTION}

Thiosemicarbazones are an important class of compounds with beneficial biological activity; they have been shown to have antitumor, antiviral, antitubercular, antibacterial, antihypertensive and antimalarial activities.

Molybdenum thiosemicarbazone complexes have attracted much interest due to their unique advantages in forming compound type $\mathrm{MoO}_{2} \mathrm{~L}$ which possess one "open" coordination sites that can be utilized for substrate binding [1], [2]. Therefore, the mononuclear dioxomolybdenum complexes might be interesting model systems. In recent years, a number of dioxomolybdenum complexes have been synthesized and characterized to mimic the biological systems [3]. There is almost universal agreement in the literature that for both the free ligands and metal complexes dialkylation of the terminal nitrogen increases in vitro cytotoxicity and that activity decreases with increasing lipophilicity of these substituents [4]. Thiosemicarbazones with an extra oxygen-containing donor to make an ONS donor set have been used successfully as tridentate chelating ligands with many metal ions, including the $\mathrm{MoO}_{2}{ }^{2+}$ core. [5]. Asymmetric molybdenum(VI) dioxo complexes of the bis(phenolate) ligands afforded high oxygen atom transfer (OAT) mechanism from dimethylsulfoxide to trimethylphosphine at $65^{\circ} \mathrm{C}$. DFT/B3LYP calculations on

Manuscript received May 26, 2015; revised July 12, 2015.

Berat İlhan Ceylan and Bahri Ülküseven are with the Istanbul University, Faculty of Engineering, Inorganic Chesmitry Division, 34320, AvcilarIstanbul, Turkey (e-mail: beril@ istanbul.edu.tr, bahseven@istanbul.edu.tr).

Ayberk Y1lmaz and Olcay Bölükbası are with the Istanbul University, Faculty of Science, Department of Physics, 34134, Vezneciler-Fatih, Istanbul, Turkey (e-mail: ayberkyilmaz@hotmail.com, olcayblkba@hotmail.com) the OAT mechanism suggested a strong trans effect [6], [7].

\section{EXPERIMENTAL PROCEDURE}

\section{A. Materials and Physical Measurements}

Microanalyses were determined on a Thermo Finnigan Flash EA 1112 Series Elemental Analyzer. UV/Visible spectra were recorded ATI-Unicam UV2 spectrophotometer. The FT-IR spectra were recorded with ATR unit by using Perkin Elmer Spectrum 400 FT Mid-IR spectrometer in the ranges of $4000-650 \mathrm{~cm}^{-1}$. $\mathrm{KBr}$ was used for Mid-IR as the beamsplitter .The ${ }^{1} \mathrm{H}-\mathrm{NMR}$ spectra were recorded on NMR spectra were obtained on a Varian INOVA $500 \mathrm{MHz}$ spectrometer relative to $\mathrm{SiMe}_{4}$ using DMSO-d $\mathrm{d}_{6}$.

\section{B. Synthesis of the Ligand}

5-chloro-4-methyl-2-hydroxybenzophenone S-methyl-4phenylthiosemicarbazone (L) was synthesized by the condensation of the 5-chloro-4-methyl-2hydroxybenzophenone and N-phenylthiosemicarbazone according to a previously published method [8], [9]. The experimental IR spectra of ligand and complex compared with the in Fig. 1.

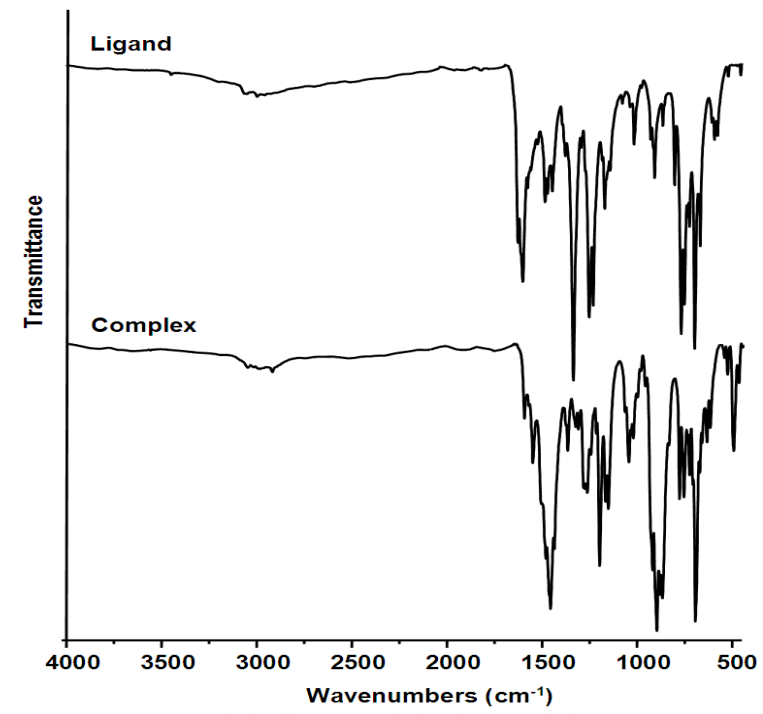

Fig. 1. FT-IR spectra of the ligand and the dioxomolybdenum (VI) complex.

Yellow-colored solid, yield: $35 \%$, m.p. at $171.2-172.6^{\circ} \mathrm{C}$. Anal. cal. for $\mathrm{C}_{22} \mathrm{H}_{20} \mathrm{ClN}_{3} \mathrm{OS}$ (409.93 g/mol), found (calc.): 65.51 (64.46) C\%; 5.01 (4.92) H\%; 10.22 (10.25) N\%; 6.88 (7.82) S\%; UV-Vis $\left(\lambda_{\max }(\log \varepsilon)\right): 242$ (4.53); 256 (4.38); 320 (3,35); 354 (4.37). ${ }^{1} \mathrm{H}-\mathrm{NMR}: 12.90$ (s, 1H, 2-OH); 8.54 (s, 1H, NH-Ph); 7.60-6.74 (12H, aromatic); 2.64 (s, 3H, 4$\left.\mathrm{CH}_{3}\right) ; 2.29\left(\mathrm{t}, 3 \mathrm{H} ; \mathrm{S}-\mathrm{CH}_{3}\right)$. 


\section{Synthesis of the Complex}

The ligand $(1.0 \mathrm{~g}, 2.43 \mathrm{mmol})$ was dissolved in pyridine (2 mL). $\mathrm{MoO}_{2}(\mathrm{acac})_{2}(0.7 \mathrm{~g}, 2.15 \mathrm{mmol})$ was added and the contents were heated at $60^{\circ} \mathrm{C}$ for 5 hours. The resulting product was subjected to dry at ambient conditions. The orange precipitate was collected by filtration. Recrystallization of the product from pyridine gave the analytical-grade pure compound (Fig. 2).

Orange-colored solid, yield: $33 \%$, m.p. at $283.8-284.1^{\circ} \mathrm{C}$. Anal. cal. for $\mathrm{C}_{27} \mathrm{H}_{23} \mathrm{ClMoN}_{4} \mathrm{O}_{3} \mathrm{~S}(614.95 \mathrm{~g} / \mathrm{mol})$, Found (calc.): 53.56 (52.73) C\%; 3.84 (3.77) H\%; 9.11 (9.11) N\%; $5.12(5.21) \mathrm{S} \%$; UV-Vis $\left(\lambda_{\max }(\log \varepsilon)\right): 222(4.56) ; 258$ (4.42); 314 (4.22); 344 (4.06); 420 (3,69); $588(2.08){ }^{1} \mathrm{H}-$ NMR: $8.56\left(\mathrm{~d}, 2 \mathrm{H}, \mathrm{C}^{1} \mathrm{H}, \mathrm{C}^{5} \mathrm{H}\right) ; 7.77\left(\mathrm{t}, 1 \mathrm{H}, \mathrm{C}^{3} \mathrm{H}\right) ; 7.56-6.79$ (12H, aromatic); 7.35-7.36 (m, 2H, $\left.\mathrm{C}^{2} \mathrm{H}, \mathrm{C}^{4} \mathrm{H}\right) ; 2.49$ (s, 3H, 4- $\left.\mathrm{CH}_{3}\right) ; 1.95$ (t, 3H; S-CH ).

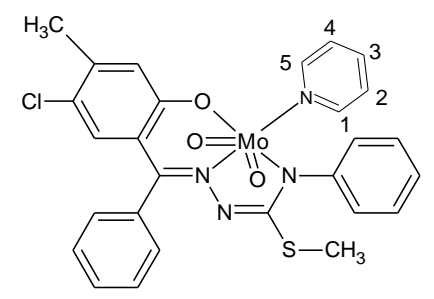

Fig. 2. The dioxomolybdenum (VI) complex.

\section{Computational Details}

Quantum chemical calculations were performed using the Gaussian 09W program package [10] with the Density Functional Theory applying the Becke3LYP functional and LANL2DZ basis set. The optimized geometry and vibrational frequencies of ligand and complex were computed. Theoretical vibrational spectra of the title compounds were interpreted by means of total energy distribution (TED) with the Scale 2.0 program [11], [12]. The calculated wavenumbers in the region between 3700 $3000 \mathrm{~cm}^{-1}$ were scaled by 0.961 [13]. Also, probable donoracceptor interactions of the complexes were examined with NBO analysis.

\section{RESUlt AND DisCUSSION}

\section{A. NMR Spectra}

The ${ }^{1} \mathrm{H}-\mathrm{NMR}$ spectra of the ligand showed the expected signals arising from the protons of phenolic, aromatic ring, $\mathrm{S}$-methyl, and $\mathrm{N}^{4} \mathrm{H}$ groups. The deprotonation of the phenolic hydroxyl and thioamide groups can be checked by the spectra. The NMR spectra of the complex clearly showed the proton signals of the coordinated second ligand (D; pyridine).

\section{B. Structural Properties}

Selected calculated bond distances, Mayer bond orders and force constants of the ligand and complex were given in Table I. After coordination, the $\mathrm{C}=\mathrm{N}^{1}, \mathrm{C}=\mathrm{N}^{2}$ and $\mathrm{C}=\mathrm{N}^{4}$ bond distances in the complex increase, whereas $\mathrm{N}-\mathrm{N}$ bond distance in the complex decrease. The $\mathrm{Mo}=\mathrm{O}$ bond lengths are 1.743 and $1.752 \AA$, respectively, exhibiting typical double bond character. According to the results of bond order and force constant values of Mo-N (pyridine) and Mo$\mathrm{N}^{1}$, these bonds show coordinative covalent bond characteristics.

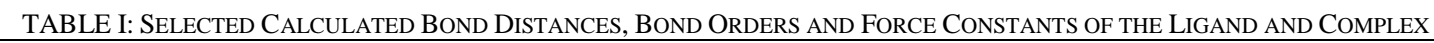

\begin{tabular}{|c|c|c|c|c|c|c|}
\hline \multirow[t]{2}{*}{ Bond } & \multicolumn{3}{|c|}{ Ligand } & \multicolumn{3}{|c|}{ Complex } \\
\hline & Distance( $(\AA)$ & Bond Order & $\begin{array}{l}\text { Force constant } \\
(\mathrm{mdyn} / \AA \mathbf{A})\end{array}$ & Distance $(\AA)$ & Bond Order & $\begin{array}{c}\text { Force constant } \\
(\mathrm{mdyn} / \AA \mathbf{A})\end{array}$ \\
\hline $\mathrm{C}=\mathrm{N}^{1}$ & (1.30923 & "1.80767455 & 9.4544 & 1.32908 & 1.45872357 & 6.7426 \\
\hline $\mathrm{C}=\mathrm{N}^{2}$ & 1.32530 & 1.64976265 & 8.7832 & 1.33264 & 1.44764168 & 5.3195 \\
\hline $\mathrm{C}=\mathrm{N}^{4}$ & 1.41728 & 0.83121717 & 6.0671 & 1.44692 & 0.79888874 & 4.5062 \\
\hline $\mathrm{N}-\mathrm{N}$ & 1.41323 & 0.92323489 & 4.5803 & 1.39479 & 0.95597784 & 3.6720 \\
\hline Mo-N(py) & & & & 2.38813 & 0.27452170 & 0.9052 \\
\hline Mo-O & & & & 2.00844 & 0.65036434 & 2.0866 \\
\hline Mo-N1 & & & & 2.31241 & 0.29522734 & 1.0443 \\
\hline Mo-N4 & & & & 2.09499 & 0.56775419 & 1.9263 \\
\hline $\mathrm{Mo}=\mathrm{O}$ & & & & 1.74302 & 1.93559490 & 7.1619 \\
\hline & & & & 1.75229 & 1.94260986 & 6.8219 \\
\hline
\end{tabular}

\section{Vibrational Analysis}

In the ligand's IR spectrum, the stretching vibrations of the $\mathrm{OH}, \mathrm{N}^{4} \mathrm{H}, \mathrm{C}=\mathrm{N}^{1}$ and $\mathrm{N}^{2}=\mathrm{C}$ groups were clearly observed. The $v(\mathrm{OH})$ and $v\left(\mathrm{~N}^{4} \mathrm{H}\right)$ bands disappeared in spectra of the complex due to the coordination of the deprotonated phenolate and $\mathrm{N}^{4}$ nitrogen. The calculated values at 941 and $915 \mathrm{~cm}^{-1}$ with the TED contribution of $84 \%$ and $45 \%$, were assigned the $\mathrm{MoO}_{2}$ anti-symmetric and symmetric stretching wavenumbers, respectively. These modes in IR spectra were observed at 930 and $908 \mathrm{~cm}^{-1}$, respectively. For the ligand, the stretching modes of $\mathrm{C}=\mathrm{N}^{1}$ and $\mathrm{N}^{2}=\mathrm{C}$ were calculated at 1599 and $1422 \mathrm{~cm}^{-1}$ with the TED contribution of $32 \%$ and $38 \%$, respectively. For complex, these modes were calculated at $1538 \mathrm{~cm}^{-1}$ and
$1452 \mathrm{~cm}^{-1}$ with the TED contribution of $22 \%$ and $36 \%$, respectively. Due to the formation of $\mathrm{Mo}-\mathrm{N}^{1}$ bond in complex, the $\mathrm{C}=\mathrm{N}^{1}$ stretching mode of complex were found to be at lower frequencies comparing with ligand. According to TED, C-S stretching modes were found at $654 \mathrm{~cm}^{-1}$ for ligand and at $663 \mathrm{~cm}^{-1}$ for complex. The bands were seen at 700 and $703 \mathrm{~cm}^{-1}$ experimentally. (Table II) The $\mathrm{N}^{1}-\mathrm{N}^{2}$ stretching modes were found at $984 \mathrm{~cm}^{-1}$ for ligand and at $1073 \mathrm{~cm}^{-1}$ for complex. These bands were observed at 1016 and $1052 \mathrm{~cm}^{-1}$ experimentally.

\section{NBO Analysis}

The Natural Bonding Orbital (NBO) analysis is important for the understanding of delocalization effect from the donor to the acceptor. The stabilization energy derived from the 
interactions between the donor and acceptor orbitals was estimated by second order perturbation interaction energy in NBO. The important interaction in the ligand having lone pair $\mathrm{S}$ (2) with that of anti pi bonding $\mathrm{C}=\mathrm{N}^{2}$, result the stabilization of $137.42 \mathrm{kcal} / \mathrm{mol}$. In the complex, the stabilization energy of these interactions obtained 23.71 $\mathrm{kcal} / \mathrm{mol}$. In the complex, other important interaction is obtained lone pair N (2) (pyridine) with that lone pair Mo (1) and lone pair Mo (3), results 36.98 and $37.41 \mathrm{kcal} / \mathrm{mol}$, respectively. The results of NBO analysis is indicate that the donor atoms transmit electron density to the Mo atom.

TABLE II: Selected Calculated WaVenumbers, EXPerimental WaVenumbers and Ted VALUes of the Ligand and Complex

\begin{tabular}{|c|c|c|c|c|c|c|}
\hline & & & Ligand & & Complex & \\
\hline Assignment & Experimental & Calculated & TED $>(\% 10)$ & Experimental & Calculated & TED $>(\% 10)$ \\
\hline 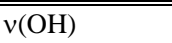 & 3434 & 3678 & (100) $v(\mathrm{O}-\mathrm{H})$ & & & \\
\hline$v(\mathrm{NH})$ & 3199 & 3369 & $(100) v(\mathrm{~N}-\mathrm{H})$ & & & \\
\hline$v\left(\mathrm{C}=\mathrm{N}^{1}\right)$ & 1625 & 1599 & $\begin{array}{l}\text { (34) } v_{\text {ring, }} \\
(32) v\left(\mathrm{C}-\mathrm{N}^{1}\right)\end{array}$ & 1600 & 1538 & $\begin{array}{l}\text { (22) } \delta\left(\mathrm{C}-\mathrm{H}_{3}\right) \text {, } \\
\text { (22) } v\left(\mathrm{C}-\mathrm{N}^{1}\right) \text {, }\end{array}$ \\
\hline$v\left(\mathrm{C}=\mathrm{N}^{2}\right)$ & 1543 & 1422 & $\begin{array}{l}(38) v\left(\mathrm{C}^{-N^{2}}\right) \\
(23) \mathrm{NH} \text { rock, } \\
(14) v_{\text {ring }}\end{array}$ & 1546 & 1452 & $\begin{array}{l}(21) v_{\text {ring }} \\
(36) v\left(\mathrm{C}-\mathrm{N}^{2}\right) \text {, } \\
(14) \delta\left(\mathrm{C}-\mathrm{H}_{3}\right), \\
\text { (13) } v(\mathrm{C}=\mathrm{N})\end{array}$ \\
\hline $\begin{array}{c}\delta(\mathrm{COH}) \\
\nu(\mathrm{CO})\end{array}$ & $1251 / 1229$ & 1139 & $\begin{array}{l}(28) \delta(\mathrm{COH}),(25) v_{\text {ring }} \\
(18) \delta_{\text {ring }},(12) \mathrm{v}(\mathrm{C}-\mathrm{O})\end{array}$ & & & \\
\hline$v(\mathrm{C}-\mathrm{S})$ & 700 & 654 & (69) $v(\mathrm{C}-\mathrm{S})$ & 703 & 663 & $(68) v(C-S)$ \\
\hline$v(\mathrm{~N}-\mathrm{N})$ & 1016 & 984 & $(53) \mathrm{v}(\mathrm{N}-\mathrm{N}),(14) v_{\text {ring }}$ & 1052 & 1073 & (37) $v(\mathrm{~N}-\mathrm{N}),(13) v_{\text {ring }}$ \\
\hline$v\left(\mathrm{MoO}_{2}\right)$ asym & & & & 930 & 941 & $(84) v(\mathrm{Mo}=\mathrm{O})$ \\
\hline$v\left(\mathrm{MoO}_{2}\right) \mathrm{sym}$ & & & & 908 & 915 & $\begin{array}{l}(45) v(\mathrm{Mo}=\mathrm{O}) \text {, } \\
(28) \gamma(\mathrm{CH})_{\text {ring }}\end{array}$ \\
\hline
\end{tabular}

\section{CONCLUSION}

New dioxomolybdenum(VI) complex with 5-chloro-4methyl-2-hydroxybenzophenone S-methyl-4-phenyl thiosemicarbazone have been characterized by analytical method and spectroscopic data and molecular structure analyses of pyridine coordinated complex. The ligand coordinated to the metal centers in the similar approach of ONN donor. Due to the neglect of vibrational anharmonicity and hydrogen bonding effect, the deviation of between calculated wavenumbers and experimental wavenumbers were higher in the region $4000-3000 \mathrm{~cm}^{-1}$ than $3000-400 \mathrm{~cm}^{-}$ 1 . The deviations in the corresponding regions were found to be below $100 \mathrm{~cm}^{-1}$. Experimental and calculated wavenumbers were found to be in a good agreement. Finally, some chemical properties, like structural parameters and frequency vibrations, obtained from calculations and experimental data were in accordance with each other.

\section{ACKNOWLEDGMENT}

Authors thank the Research Project Fund of Istanbul University for financial support.

\section{REFERENCES}

[1] M. D. Shoeili, M. Boghaei, M. Amini, M. Bagherzadeh, and B. Notash, "New molybdenum(VI) complex with ONS-donor thiosemicarbazone ligand: Preparation, structural characterization, and catalytic applications in olefin epoxidation," Inorg. Chem. Commun., vol. 27, pp. 26-30, 2013.

[2] J. Pisk, B. Prugovečki, D. Matković Čalogović, R. Poli, D. Agustin, and V. Vrdoljak, "Charged dioxomolybdenum(VI) complexes with pyridoxal thiosemicarbazone ligands as molybdenum $(\mathrm{V})$ precursors in oxygen atom transfer process and epoxidation (pre)catalysts," Polyhedron, vol. 33, pp. 441-449, 2012.

[3] H. G. Zhang, "Preparation, characterization, and crystal structures of dioxomolybdenum(VI) complexes with tridentate Schiff base ligands," Synth. React. Inorg. Met.-Org. Nano-Met. Chem., vol. 43, pp. 933-936, 2013.
[4] D. Eierhoff, W. C. Tung, A. Hammerschmidt, and B. Krebs, "Molybdenum complexes with O, N, S donor ligands as models for active sites in oxotransferases and hydroxylases," Inorganica Chimica Acta, vol. 362, pp. 915-928, 2009.

[5] J. R. Dilworth and R. Hueting, "Metal complexes of thiosemicarbazones for imaging and therapy," Inorg. Chim. Acta, vol. 389, pp. 3-15, 2012.

[6] M. R. Pedrosa, J. Escribano, R. Aguado, V. Diez, R. Sanz, and F. J. Arnaiz, "Dinuclear oxomolybdenum(VI) acetylacetonates: Crystal and molecular structure of $\mathrm{Mo}_{2} \mathrm{O}_{5}(\mathrm{acac})_{2} \mathrm{~L}_{2}$ ( $\mathrm{L}=\mathrm{D}_{2} \mathrm{O}$, DMF)," Polyhedron, vol. 26, pp. 3695-3702, 2007.

[7] R. Mayilmurugan, B. N. Harum, M. Volpe, A. F. Sax, M. Palaniandavar, and N. C. Mösch-Zanetti, "Mechanistic insight into the reactivity of oxotransferases by novel asymmetric dioxomolybdenum(VI) model complexes," Chem. Eur. J., vol. 17, pp. 704-713, 2011.

[8] B. İ. Ceylan, Y. D. Kurt, and B. Ülküseven, "Synthesis and characterization of dioxomolybdenum(VI) chelates with dibasic form of 5-bromo-2-hydroxybenzophenone-S-methyl/ethyl/4-phenylthiosemicarbazones," Rev. Inorg. Chem., vol. 29, no. 1, pp. 50-67, 2009.

[9] B. İ. Ceylan, Y. D. Kurt, and B. Ülküseven, "Synthesis and characterization of new dioxomolybdenum(VI) complexes derived from benzophenone-thiosemicarbazone $\left(\mathrm{H}_{2} \mathrm{~L}\right)$. Crystal structure of $\left[\mathrm{MoO}_{2} \mathrm{~L}(\mathrm{PrOH})\right]$," J. Coord. Chem., vol. 62, no. 5, pp. 757-766, 2009.

[10] G. Scalmani et al., Gaussian 09, Revision A.02, Gaussian Inc., Wallingford CT, 2009.

[11] G. Pongor, Department of Theoretical Chemistry, Scale 2, Eötvös Lorand University, Budapest, 1978.

[12] G. Pongor, G. Fogarasi, I. Magdo, J. E. Boggs, G. Keresztury, and I. S. Ignatyev, "Theoretical prediction of vibrational spectra, a priori scaled quantum mechanical (SQM) force field and vibrational spectra of pyrimidine," Spectrochim. Acta, vol. 48 A, pp. 111-119, 1992.

[13] NIST. (May 2015). Precomputed vibrational scaling factors. [Online]. Available: http://cccbdb.nist.gov/vibscalejust.asp.

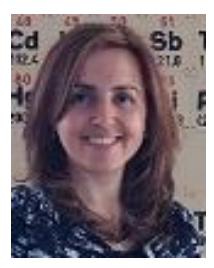

Berat İlhan Ceylan was born in Elazig, Turkey on December 18, 1978 who had her bachelor's degree in the Department of Chemistry in Istanbul University, Turkey in 1999. She had her MSc degree in Organic Chemistry Division in Istanbul University in 2004 and she received her $\mathrm{PhD}$ in Inorganic Chemistry Division of the same university in 2009. Her major areas of interest include transition metal chemistry, synthesis of 
especially molibdenum and vanadium complexes. She has worked for a pharmacy company as a chemist for two years. She is a research assistant at Chemistry Department, Istanbul University, Turkey since 2002.

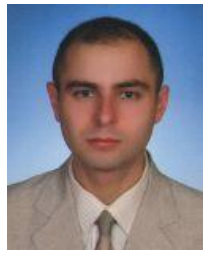

Ayberk Yılmaz was born in Istanbul, Turkey on June 25, 1978 who had his bachelor's degree in the Department of Physics in Istanbul University, Turkey in 1999. He had his MSc degree in Physics Division in Istanbul University in 2003 and he received his $\mathrm{PhD}$ in Physics Division of the same university in 2007 . He is interested in vibrational spectroscopy and quantum chemical calculations. He is an assistant professor at Physics Department, Istanbul University, Turkey since 2009.

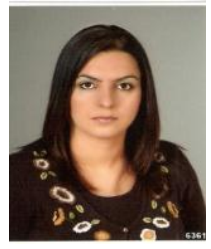

Olcay Bölükbașı was born in Malatya, Turkey on August 13, 1979 who had her bachelor's degree in the Department of Physics in Istanbul University, Turkey in 2000. She received her $\mathrm{PhD}$ in Physics Division of the same university in 2007. She is interested in vibrational spectroscopy and quantum chemical calculations. She is an associate professor at Physics Department, Istanbul University, Turkey since 2013. 
